\title{
Research on Virtual Simulation System of Campus Emergency Drill
}

\author{
Liang Huan ${ }^{1}$, Wang Wenju ${ }^{1}$, Zhang Ruojun ${ }^{1,}$ Han Hao $^{1}$ and Deng Biao ${ }^{1+}$ \\ ${ }^{1}$ Universty of Shanghai for Science and Technology
}

\begin{abstract}
At present, domestic and foreign campus emergency drills are for on-site rehearsal, which is not only a waste of manpower and material resources and little effect. Based on this situation, this paper proposes a campus emergency drilling virtual simulation system, this system mainly includes the campus roaming, emergency plan demonstration, safety education of three modules, using 3DSMAX modeling and virtual roaming technology, this system can build a realistic virtual campus scene, the scene of the accident showed in the computer, so that the users can interact with the simulated scene, in order to reduce the waste of resources, to achieve the effects of emergency drills, evacuation, safety education. The experimental results show that the campus emergency drilling virtual simulation system proposed in this paper, can be used to restore the accident scene in a computer. Users can operate autonomously, so that it can achieve the effect of reducing waste of resources, plan demonstration, learning safety knowledge. What's more, it can improve the safety awareness of teachers and students and provide a way for the decision makers to deal with the accident.
\end{abstract}

Keywords: Campus emergency; evacuation; virtual simulation; roaming; 3D modeling.

\section{Introduction}

With the improvement of our education, more students have the opportunity to enter the campus to receive higher education. At the same time, the growth of the number of students makes fire, stampede and other emergencies occur frequently, more and more colleges and universities began to attach importance to the development of campus safety emergency drills. However, today's domestic and foreign university simulation treatment on fire, stampede and other emergencies are only for the rehearsal, this method will spend a lot of manpower and resources, and can not carry out a full range of emergency drills, will cause a waste of resources, and even affect the quality of the environment for the simulation of fire and explosion class. In order to improve the decision-making ability of the administrators and the students' ability to deal with emergencies and simulate the emergencies, it is very important to make a campus safety emergency drill system which can be operated by itself.

In 2016, Serkan Ada et al. Research on factors affecting students' receiving campus emergencies emergency notice, they investigated the response of 500 students to receive emergency notification in the five cases, and concluded that it is more helpful for students to receive emergency notification through the social network (SNS) [1] .

In 2016, YongQian Ma, Jiyu An used GIS and JDL technology, according to the actual situation and demand, making research on campus emergency response system, They redefined the fusion of five kinds of information structure, so that the information fusion framework of campus emergency demand system is improved. The study makes the campus security and network information technology more closely linked. It is of great significance to prevent campus emergencies and strengthen campus security and stability [2].

In 2016, Bao Rong proposed a 3D virtual campus study system based on fire emergency drills. She mainly analyzed the feasibility of 3D virtual fire emergency drilling system, and discussed the role of [in the fire safety and design[3].

Corresponding author. Tel.: + 13636675266 .

E-mail address: wangwenju666@163.com 
In 2015, Bixiang LI made study on the emergency of traffic problems on campus. A complex information system is proposed to deal with the emergency. Bixiang LI analyzed the differences between urban traffic accidents and traffic accidents on campus. It provides a good way for us to deal with emergencies [4].

In 2014, Robin Hattersley gray pointed out that higher education institutions wish to seek a more perfect campus safety emergency system, to improve the ability to deal with emergencies on campus[5].

In 2011, Jihao Lvmei Subing et al. According to the concept, characteristics, classification and function of campus emergency system, based on the two aspects of emergency management and emergency management, they designed a management system for the prevention of emergency and emergency risk assessment[6].

In 2015, Yang Shuai studied the current situation of University emergencies in recent years and the way to deal with the crisis, he found that the key to reduce the probability and harm of campus emergency is to make efforts in the cause of the unexpected events. So that the development of effective crisis response strategy is the key [7].

In 2011,Jiang Nengxin created a simulation of student apartment emergency evacuation simulation system based on Delta 3D. The system simulates the situation of the student dormitory emergency .He used 3D Max to create the effect of fireworks, this system had strong interaction and operation [8].

In 2015, Wu Huihuang using the GIS virtual reality technology to study on the virtual campus crowd evacuation drills, using the shortest path method in data analysis method to choose the optimal evacuation path. The system realized the continuous group and individual evacuation. Through multiple simulation, this system enabled the school staff to master the emergency evacuation plan, and improve the ability to deal with personnel emergency. The above systems solved the situation that the school will waste a lot of manpower and material resources in the field of practice, but the simulation of the system is relatively simple, and the simulation scene is not rich enough [9].

In 2005, Liu Kun and Wang Guangsheng proposed a design of virtual training system for fire threedimensional real-time rendering technology based on the ways of using some algorithms of real-time rendering, artificial intelligence and pattern recognition to establish virtual fire training system combined with the model of fire hazards [10].

In 2012, Mei Yulong studied the computer 3D simulation system of emergency drills, mainly analyzed the advantages and disadvantages of traditional emergency drills and the existing computer technology development present situation. He researched and developed an emergency drilling system based on computer virtual reality technology. Mei Yulong discussed the technical feasibility of the system, system structure, operation mode and system advantage, finally he obtained the computer simulation system of three dimensional emergency drilling and the traditional emergency drills are complementary, and fully exploited the great potential of emergency drills in production safety and social security [11].

In summary, many scholars at home and abroad for the study of campus emergency rehearsal mostly stay in the crisis awareness education, preparation of contingency plans or practical exercises and so on. The research on Virtual Emergency rehearsal is still lack, and the specific implementation of the system has not been studied much, many areas of research are also relatively narrow, cannot contain many unexpected situations may occur in the campus. Therefore, it is necessary for us to study the campus emergency drilling system.

\section{System Function Structure.}

The virtual simulation system of campus emergency drill can be divided into three parts:

- campus roaming: to understand the basic situation of the school;

- demonstration of emergency plans: to simulate the different situations, and make corresponding measures;

- safety knowledge education: in the form of text, audio or video to the operator safety knowledge education. 
The system function structure is shown in Fig 2.1:

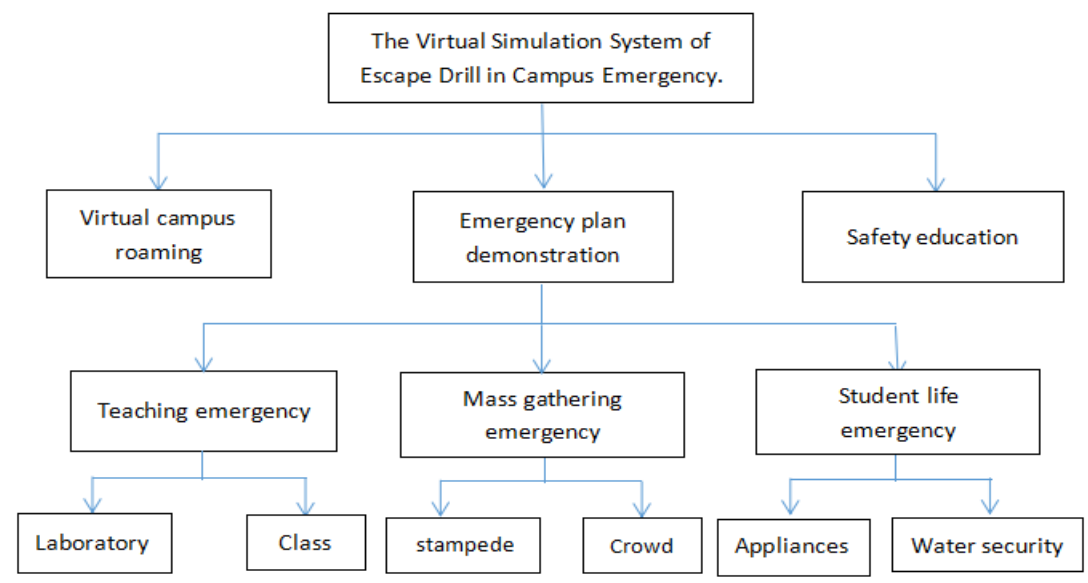

Fig .2.1: The system function structure

\subsection{Campus roaming}

In the campus, it is necessary to understand the situation of the school, for which we set up a map to provide users with a holistic view, to prevent the lost. In addition, also set up five kinds of scene roaming: teaching scene roaming, large assembly roaming, campus main road roaming, teachers and students dormitory roaming, evacuation sites roaming. Only by understanding the environment can we make decisions more quickly and accurately.

Through roaming, users can not only quickly understand the school profile, at the same time, it is easy to grasp the places that prone to unexpected situations and safety zone of the school. When danger comes, the school administrators can react in the first place to minimize risk and loss.

The campus roaming structure is shown in Fig 2.2.

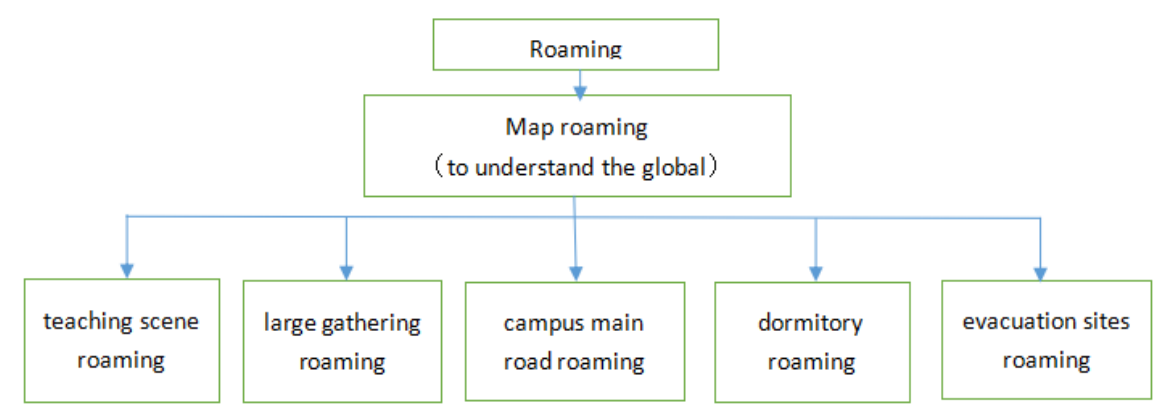

Fig. 2.2: The campus roaming structure

\subsection{Emergency plan demonstration}

- Teaching emergent situation demonstration

In the teaching process, the use of electricity, experimental operation is not standardized, improper use of chemical products, such as behavior has brought great security risks. In order to prevent the occurrence of such incidents as well as in the event of an accident can be handled accurately, A teaching scene emergency situation demonstration was be made.

In the classroom to restore the real situation of the accident, not only can cause the user's concern about the safety of the classroom, but also to achieve the effect of real exercise. In the light of several kinds of unexpected situations, such as the electricity consumption is not standardized, the use of chemical products is improper, the experimental operation is not standard, the corresponding scenario simulation is made and the solution is worked out.

- The large gatherings demonstration

The school held a large rally, often the personnel density, population mobility, in this case it is prone to congestion, stampede and other events, how to evacuate the teachers and students that occurs is very important, and this situation is not a rehearsal drill site. To this end, a simulation of a large rally scene and 
the true reduction of emergency are conducted, and the corresponding solution is formulated. It is convenient for the users to understand the situation of the large gatherings and improve the emergency ability of the teachers and students.

Students dormitory sudden situation demonstration

It is often seen the accidents caused by the improper use of electricity and water in students dormitory. We should attach great importance to the safety problem of accommodation, prevention is a very important part. Dealing with the accident is also very important. The corresponding simulation and reduction for the students in the different emergency situations is made, hoping to improve the safety awareness of students in the process of accommodation and emergency response capacity of the dormitory.

\subsection{Safety knowledge education}

We set up a security education section in the system to provide some video and text information about security knowledge.

The system can be set up in the security education to allow users to use the system before the understanding of some security knowledge. After the users have completed a variety of unexpected situations after the rehearsal, the system conducts safety education for users, indicating that the users don't make nonstandard operation and behavior in the previous rehearsal process, improving the users' safety awareness.

\section{System Function Realization}

The function of this system is divided into three parts: the realization of campus roaming function, the realization of typical emergency plan demonstration function, and the realization of safety knowledge education.

The process flow of the system is shown in Fig 3.1. Firstly, the emergency scene is restored, and then the fault is judged. This system aims at the different roles also put forward different ideas of accident response: teachers should contact the relevant departments to deal with the accident after the accident, and evacuate the students, troubleshooting by professional personnel to ensure the safety of the case; for students in the accident should not panic, otherwise it will cause serious the consequences should remain calm, listen to the relevant professional guidance, orderly evacuation.

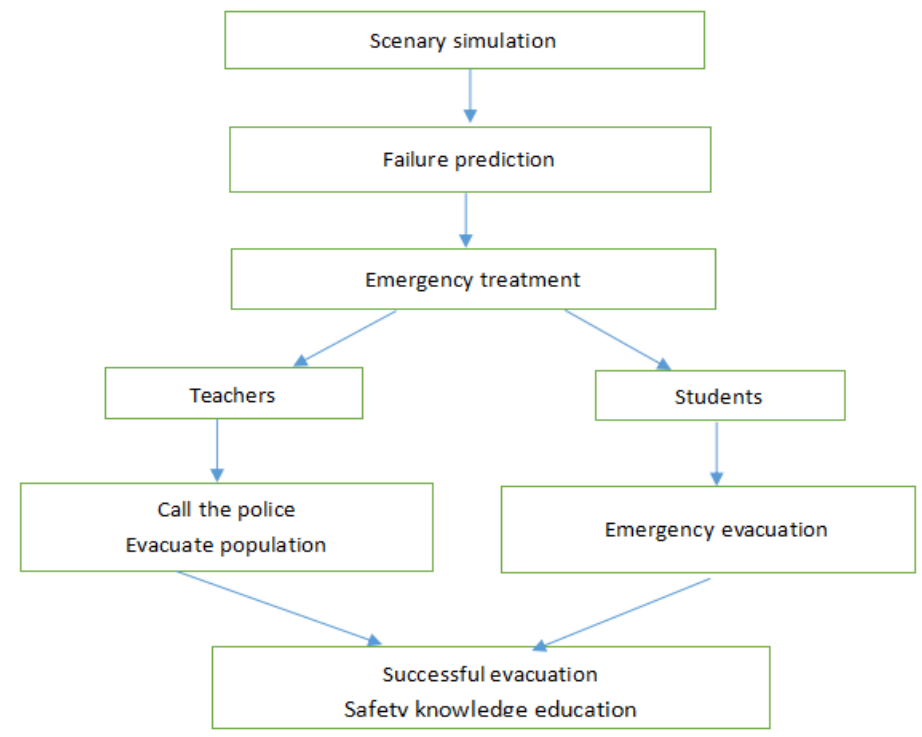

Fig. 3.1: System function realization flowchart

\subsection{Campus roaming function realization}

- campus modeling :

1) Using the 3Ds max to create the campus model by scaling the existing campus plan.

2) Taking photos of the buildings, in the campus, manipulating the photos by Photoshop to make texture mapping. 
3) Creating the virtual campus by the way of geometric modelling (including the buildings, roads and plants).Then mapping rendering and lighting the model to make the models be more near to the reality, so that we can make a realistic 3D models.

- Roaming realization roaming by prescribed path or at user's own

1) Importing the FBX formatting campus model and Mesh to Terrain. Unity package plug-in into the unity software.

2) Changing the campus model to the terrain we need.

3) Importing the character resource bundle into the unity. Putting the first-person perspective on the terrain by clicking.

4) Creating the operation interface

5) Users select or change five basic roams by clicking the control of operation interface or keyboard, moving straight or back etc basic operations.

\subsection{Typical contingency plan demonstration function realization process}

Simulate Emergency Situation

In the model of the teaching experiment what we established, we use Unity Particle system to simulate the critical situations in laboratory, such as burst and fire accident ,the process of use flame arrestor to put out a fire, and the situations about the fire accident.

Analyze the Cause

After the burst and fire accident, we must analyze the reasons about the accident. This system can in accordance with specific conditions to offer some solutions to resolve opposite accident. Such as use water to put out a fire, foam fire-fighting and so on .Then, security office can take a different approaches to resolve the accidents.

Relevant Staff 's Solutions

After the burst and fire accident, system simulate the situation about the laboratory staff 's treatment measure. This system uses 3DSMAX to set up some models about teachers and students and import them into Unity. Then, system pop-up windows hint teachers to contact the security office, and following the user's operation point of sight will change, in the key point will pop- up windows to hint users to guidance teachers and students to evacuate. In the case of ensuring their own safety, laboratory professionals to exclude the fault; students follow the teachers' guide to evacuate and go to the safety place.

\subsection{Safety knowledge}

We import some words, audio and video about safety knowledge into the system, users can in accordance with specific conditions choice appropriate information to study.

\section{Experimental Results and Analysis}

In order to verify the effectiveness of the system, this system simulates a typical case of laboratory explosion and fire, the experimental results are shown in Fig 4.1 - 4.8.

Among them, Fig 4.2 for the campus overlooking the map, can be seen from the figure, a complete campus scene is established, which includes teaching building, dormitory, playground, laboratory buildings, roads and other scenes, represents a typical university campus; Fig 4.3 is the teaching building of local detail diagram, the system simulation the reality of the teaching environment.

Fig 4.1 shows the interface design part of the campus emergency drill system.

Click on the "roaming" button, enter the virtual campus roaming: Fig 4.4 to 4.6 for the campus roaming map, showing the operator can go to every corner of the campus through roaming: among them, Fig 4.4 is the prospect of the teaching building on the campus roaming, Fig 4.5 and Fig 4.6 for building close roaming;

Click the "Preview" of campus emergency exercises rehearsal: Fig 4.7 and Fig 4.8 are the operating results of click "Preview" button on the map, the system can restore the scene of the accident and fire rehearsal, the particle system successfully simulated laboratory of explosion fire and foam fire extinguisher extinguishing system success at the scene of the explosion. When an explosion occurred in the laboratory, 
automatic power-off switch. Under the condition of laboratory personnel to ensure their own safety, they use a foam extinguisher to extinguish the fire until the fire is extinguished;

Click on the "safety knowledge" button, as shown in Fig 4.9 and Fig 4.10, the system pop-up text, audio, video for the corresponding emergency safety knowledge education.

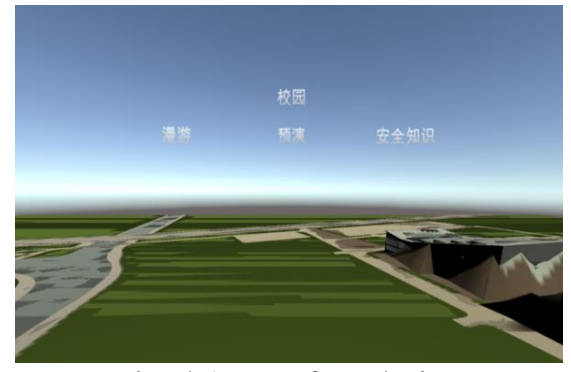

Fig. 4.1: Interface design

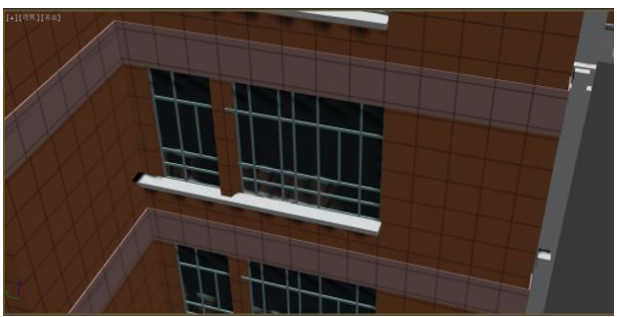

Fig. 4.3: Details of the campus model

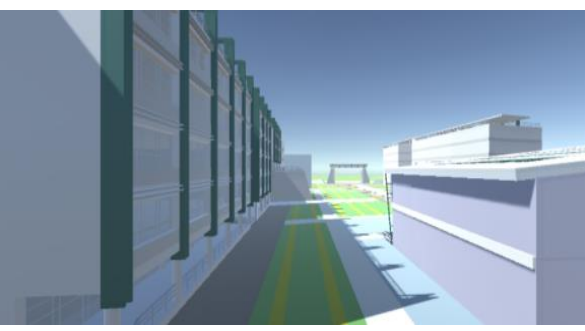

Fig. 4.5: Campus roaming

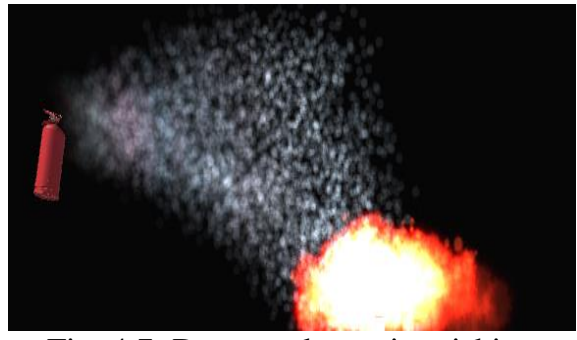

Fig. 4.7: Dry powder extinguishing

Laboratory fire safety management systen

First, clear fire safety, fire prevention responsibility, always check fire equipment, not for any reason misappropriation of fire equipment for it, found that does not meet the requi rements, timely replacement.

Second, strictly abide by the electricity management system, not allowed to pull wires, is prohibited in all rooms have illegal use of electrical appliances,

violation of safe use of electricity.

Fig. 4.9: Safety education

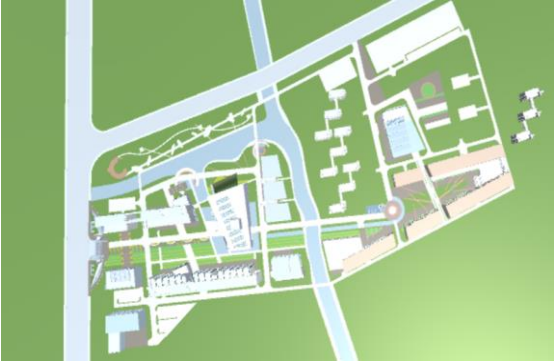

Fig. 4.2: Campus panoramic view

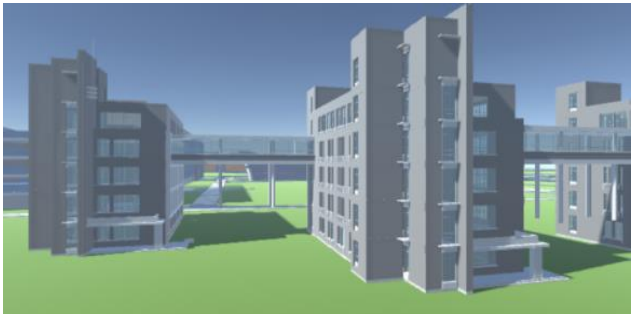

Fig. 4.4: Campus roaming

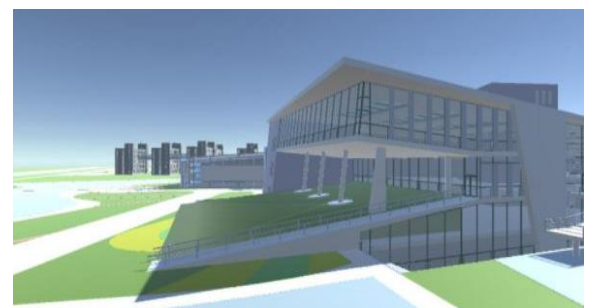

Fig. 4.6: Campus roaming

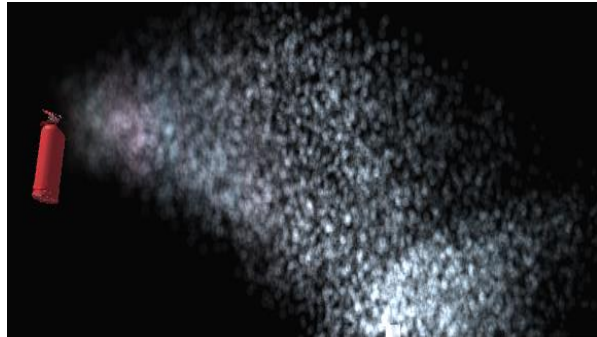

Fig. 4.8: Dry powder extinguishing

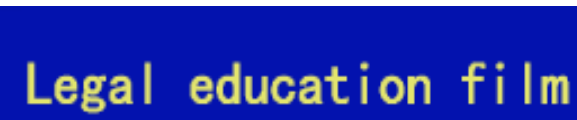

\section{Creating}

\section{a safe campus}

Fig. 4.10: Safety education

Through the above illustration and analysis, this system realizes the campus roaming, typical emergency drill, safety education function, providing a effective virtual simulation system for campus emergency drill for the school staff and students. 


\section{Conclusion}

A campus emergency drilling virtual simulation system is put forward in this paper, the system can visually show the campus landscape and teaching facilities to carry out campus emergency simulation exercises. The users can also interact with the virtual environment through the computer, and can be repeatedly. It greatly reduces the waste of human resources and physical resources caused by field exercises, and designs several modules of safety education, accident simulation and campus roaming from the aspects of prevention, emergency response and post treatment. This system can let users carry out safety education in order to achieve the effect of nip in the bud. The simulation of the effect of the accident and the simulation of the response measures provide a way for the teachers and the students to deal with the accident. After the treatment, the combination of campus evacuation and safety knowledge education, so that users have a more profound impression of similar incidents and improve safety awareness.

\section{Acknowledgements}

This work was supported in part by a grant from the Innovation and Entrepreneurship Project of College Student of University of Shanghai for Science and Technology (No.XJ2016234)and the Innovation and Entrepreneurship Project of College Student of Shanghai .

\section{References}

[1] Serkan Ada, Raj Sharman, Wencui Han and Joseph A Brennan," Factors Impacting the Intention to Use Emergency Notification Services in Campus Emergencies: An Empirical Investigation ,” IEEE Trans. Prof. Commun, vol.59, no.2, June 2016.

[2] Yongqiang Ma, "Jiyu An,Research on Structure of Information Fusion of Campus Emergency", IEEE Trans. Prof. Commun, vol.59, no.2, June 2016.

[3] Bao Rong, "Fire Drill System Research Based on 3D Virtual Campus," Journal of Lanzhou Petrochemical College of Technology, vol.16, no.2, Mar 2016.

[4] Bixiang LI , "Traffic Safety Characteristics Analysis and Emergency Management Research on Campus," 2015 Second International Symposium on Dependable Computing and Internet of Things

[5] R.H.Gray.(2014). "Campuses Continue to Invest in Emergency Notifications System and Upgrades."Campus Safety Mag. [Online].Available: http://www.campussafetymagazine.com

[6] Jihao Lvmei Subing, "Notice of Retraction Study on risk management of campus emergency", May 2011

[7] Yang Shuai, "University campus emergencies and crisis management" [J]. human resource management, Mar 2015

[8] Jiang Nengxing, "Evacuation simulation system" [J]. modern computer student apartments, Feb 2011

[9] Wu brilliant, "Research on the emergency evacuation system of 3D Virtual Campus Based on" [J]. GIS Journal of Taiyuan City Vocational College, Vol.17, No.12, Dec 2015

[10] Liu Kun, Wang Guangsheng, “ Design of virtual fire training system based on 3D real-time rendering technology"'J]. computer application, Vol.25, No.8, Aug 2005

[11] Mei ERON, "Research on three dimensional simulation system of emergency drilling computer" [J]. China safety science and technology, Vol.8, No.4, April 2012 